\title{
Complete pathological response following neoadjuvant FOLFIRINOX in borderline resectable pancreatic cancer - a case report and review
}

Mišo Gostimir ${ }^{1}$, Sean Bennett ${ }^{2}$, Terence Moyana ${ }^{3}$, Harman Sekhon ${ }^{3}$ and Guillaume Martel ${ }^{4^{*}}$

\begin{abstract}
Background: Pancreatic cancer is among the top 5 most common cancers worldwide, but is particularly devastating due to its insidious nature. Complete surgical resection remains the only potential curative treatment, although only $20 \%$ of patients present with a resectable tumor. Patients may alternatively present with borderline resectable pancreatic cancer or locally advanced pancreatic cancer and can be offered treatment with neoadjuvant intent. The effectiveness of these treatments is unclear and there is a paucity of data to suggest one optimal treatment approach.
\end{abstract}

Case presentation: We describe a 61-year-old female who presented with a two-week history of obstructive jaundice in the context of vague abdominal pain that had been ongoing for years prior to her visit. CT scan of the abdomen confirmed a hypovascular mass in the uncinate process consistent with borderline resectable pancreatic cancer. Pancreatic adenocarcinoma was confirmed with endoscopic ultrasound guided fine-needle aspiration cytology. Following multidisciplinary discussion, it was recommended that she undergo treatment with FOLFIRINOX. After a total of 13 cycles, follow up CT revealed that the lesion had decreased in size and she was offered resection as a potentially curative treatment. She underwent pancreaticoduodenectomy. Final pathology report revealed no evidence of residual adenocarcinoma (ypT0 ypNO (0/23)). The patient remains disease-free 15 months following surgery.

Conclusion: To date, there have been very few reports of a complete pathological response following neoadjuvant therapy in borderline resectable or locally advanced pancreatic cancer. This report describes a unique case of a complete pathological remission in a patient with borderline resectable pancreatic cancer following FOLFIRINOX therapy alone and adds to the growing base of evidence meriting the initiation of clinical trials to assess the efficacy of FOLFIRINOX in these subsets of pancreatic cancer.

Keywords: FOLFIRINOX, Pancreatic cancer, Complete pathological response, Neoadjuvant therapy, Locallyadvanced, Borderline resectable, Case report

\footnotetext{
* Correspondence: gumartel@ottawahospital.on.ca

${ }^{4}$ Department of Surgery, Liver and Pancreas Unit, University of Ottawa, 501

Smyth Rd, K1H 8 L6 Ottawa, Canada

Full list of author information is available at the end of the article
} 


\section{Background}

Pancreatic adenocarcinoma is one of the top five causes of cancer death worldwide. It is particularly devastating due to its insidious progression. The red flag symptoms prompting diagnosis often appear only once the disease has already progressed or metastasized. As a result, only $10-20 \%$ of pancreatic cancers are resectable at the time of presentation and the overall 5-year survival rate is less than $5 \%[1,2]$.

Early intervention in non-metastatic pancreatic cancer is crucial as metastases have been shown to occur unexpectedly before clinical detection is possible [3-5]. Surgical resection is thought to be the only curative treatment for pancreatic adenocarcinoma and offers a five year survival rate of $10-15 \%[1,6,7]$. Neoadjuvant chemotherapy is often implemented in an effort to increase the incidence of $\mathrm{R} 0$ resections, reduce local recurrences, treat occult micrometastases, and to downstage a borderline resectable tumor to the point of possible resection [1].

A subset of patients is considered to have borderline resectable pancreatic cancer, which can be classified using three main staging systems. The first staging systems were established by M.D. Anderson and the National Comprehensive Cancer Network. A third system was put forth by the Americas Hepatopancreatobiliary Association/Society of Surgical Oncology/Society for Surgery of the Alimentary Tract in 2009 and was ultimately adopted by the National Comprehensive Cancer Network. Based on the M.D. Anderson criteria, borderline resectability can be defined as tumor abutment of $\leq$ $180^{\circ}$ of the circumference of the superior mesenteric artery (SMA), short-segment encasement or abutment of the common hepatic artery (typically at the gastroduodenal origin), or short-segment occlusion of the superior mesenteric vein or portal vein with suitable vessels above and below [8]. The current National Comprehensive Cancer Network system is largely similar to the M.D. Anderson criteria except that abutment $\left(\leq 180^{\circ}\right)$ or encasement $\left(>180^{\circ}\right)$ of the superior mesenteric vein/portal vein without vein contour irregularity is considered borderline resectable. Thus, non-occlusive involvement of the superior mesenteric vein or portal vein is considered only borderline resectable by the National Comprehensive Cancer Network criteria, but resectable by the M.D. Anderson criteria [8-11]. Patients with borderline resectable pancreatic cancer typically undergo chemotherapy and/or chemoradiation as a neoadjuvant approach, followed by radical surgical resection.

About $30 \%$ of patients have locally advanced pancreatic cancer $[2,5]$ which is defined by the M.D. Anderson criteria as tumor encasement of the SMA beyond $180^{\circ}$, encasement of the celiac artery or hepatic artery, or occlusion of the superior mesenteric vein or portal vein, all in the absence of metastatic disease [8]. Patients with locally advanced pancreatic cancer are generally treated with chemotherapy or chemoradiation. In the majority of patients, this is considered palliative treatment, although a small subset of patients who see a radiological response may eventually be considered for surgical resection.

Pathologic complete response (pCR) is used to refer to a neoplastic tissue specimen with no residual viable invasive adenocarcinoma cells within the parenchyma [12]. For several different cancer types, $\mathrm{pCR}$ is associated with lower frequencies of local recurrences, distant metastases, and overall better survival rates. The significance of pCR in pancreatic cancer has also been demonstrated by an association with high survival rates $[12,13]$. To our knowledge, while there have been several reports of a pCR following neoadjuvant therapy in borderline resectable or locally advanced pancreatic cancer [5, 14-20], there has been only one case report of a patient who achieved pCR with FOLFIRINOX alone [21]. This article describes the second report of a well documented, histologically proven pCR following systemic treatment with FOLFIRINOX.

\section{Case presentation}

A 61-year-old French Canadian female presented to hospital with a two-week history of obstructive jaundice, pruritus, tea-coloured urine, acholic stools, fatigue, anorexia, and unintentional weight loss. Her history also included vague abdominal pain that had been ongoing for years prior to her visit, although the pattern of pain did not change with the onset of jaundice. Her past medical history included type 2 diabetes mellitus and hypertension. She did not have a personal history of cancer, but her family history included two aunts who had pancreatic cancer in their sixth decades of life. She denied any tobacco, alcohol, or recreational drug use.

Abdominal ultrasound revealed a lesion in the uncinate process of the pancreas. A subsequent CT scan of the abdomen confirmed a fairly well circumscribed hypovascular mass in the head and uncinate process of the pancreas, radiographically consistent with pancreatic adenocarcinoma (Fig. 1a). The mass encircled the first jejunal branch of the superior mesenteric artery by approximately $180^{\circ}$. Endoscopic retrograde cholangiopancreatography (ERCP) was ultimately unsuccessful due to inability to cannulate the common bile duct. The pancreatic duct was patent and could be cannulated but seemed to end abruptly.

The patient underwent an endoscopic ultrasound, which revealed a $4.8 \times 3.5 \mathrm{~cm}$ hypoechoic mass in the pancreatic head/uncinate process along with numerous cystic changes in the body, tail, and distal tail of the pancreas, measuring $2.4 \mathrm{~mm}, 3.9 \mathrm{~mm}$, and $4.3 \mathrm{~mm}$, 


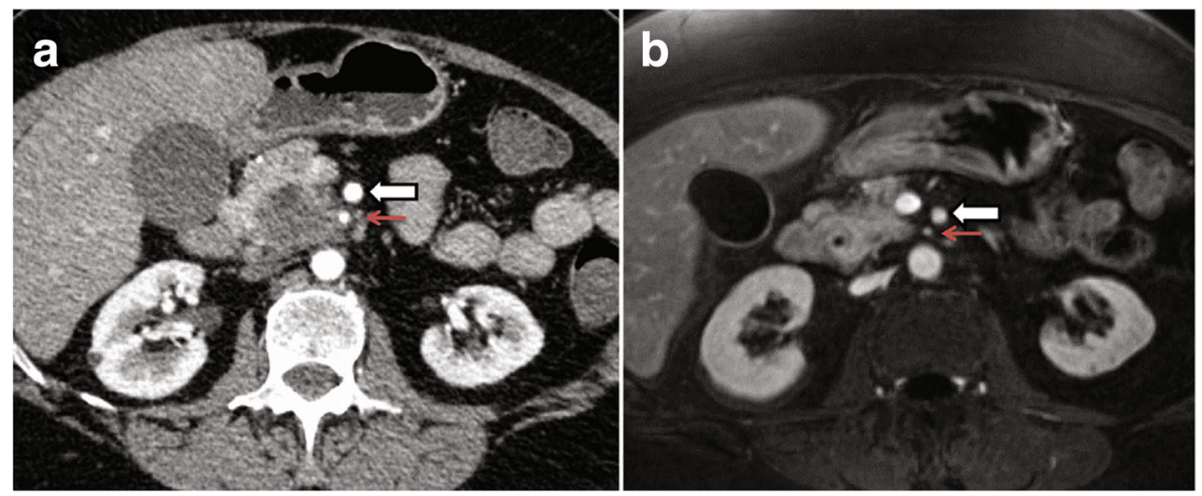

Fig. 1 Abdominal CT scans. a The mass is separate from the celiac axis an there is loss of a fat plane between the mass and SMA (white arrow) with less than $90^{\circ}$ involvement of its circumference. The first arterial jejunal branch (red arrow) is also encased with tumor. There is also mild narrowing of the medial aspect of the superior mesenteric vein where the tumor abuts around $90^{\circ}$ of its circumference. The pancreatic duct is dilated, measuring up to $6 \mathrm{~mm}$. b Following 9 cycles of FOLFIRINOX, the follow up MRI reveals that the head of the pancreas has indistinct margins, but has clearly diminished in size. The measured size is $2.7 \times 2.3 \mathrm{~mm}$ (prior: $3.9 \times 3.2 \mathrm{~mm}$ ). Pancreatic ductal dilatation has subsided, indicating response to treatment

respectively. Fine-needle aspiration (FNA) biopsy at the time of endoscopic ultrasound demonstrated cytology consistent with adenocarcinoma (Fig. 2).

At the time of diagnosis, the patient's functionality was consistent with Eastern Cooperative Oncology Group (ECOG) grade 1: restricted in physically strenuous activity, but ambulatory and able to carry out light work. The CA19-9 levels were ordered but deferred by the patient. Her total bilirubin at the time of diagnosis was
$160 \mu \mathrm{mol} / \mathrm{L}$. The patient underwent placement of a percutaneous transhepatic biliary drainage catheter, with resolution of her jaundice. The patient was reviewed at a weekly hepatobiliary and pancreatic cancer multidisciplinary conference. Consensus was that her tumor was borderline resectable on the basis of partial encasement of the superior mesenteric artery. Although there was encasement of the first jejunal branch, the tumor was staged based on abutment of less than $\leq 180^{\circ}$ of the

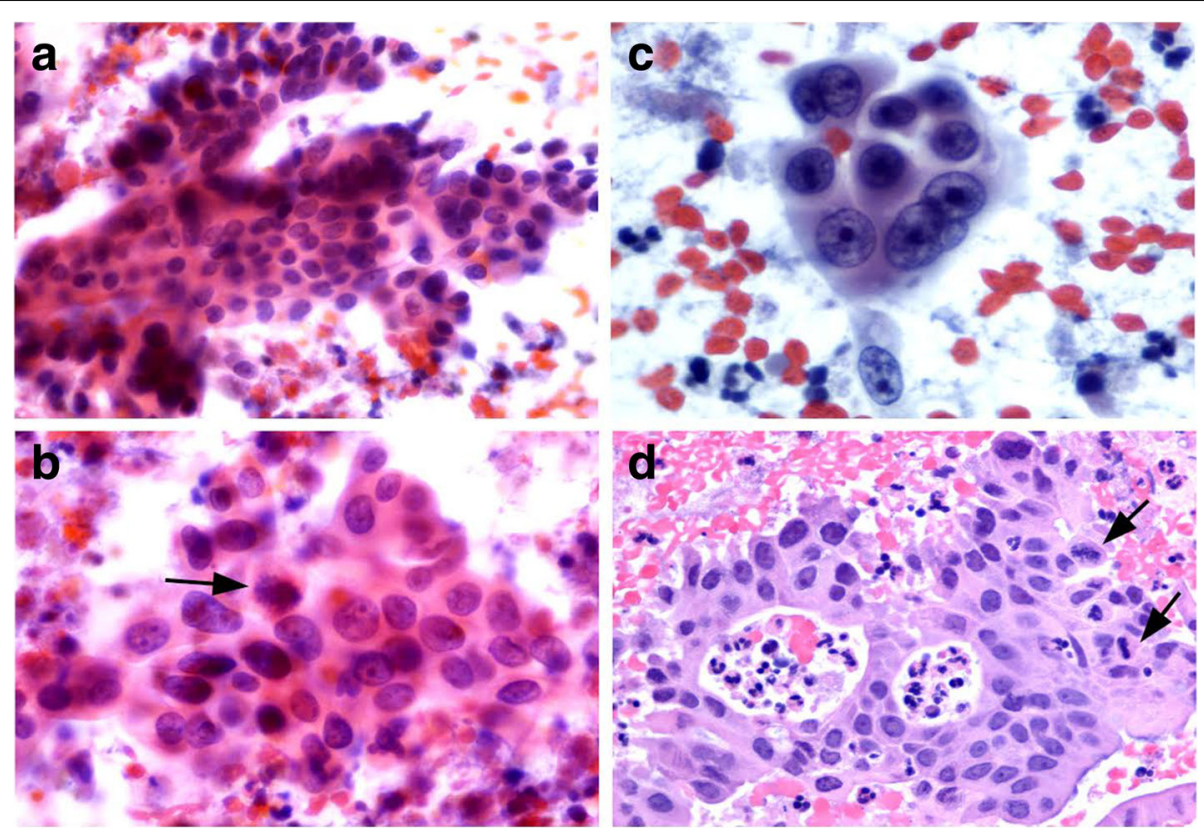

Fig. 2 Photomicrographs showing cytomorphological findings of endoscopic ultrasound guided fine needle aspirate of pancreatic

adenocarcinoma. a Cellular aspirate depicting glandular cells arranged in complex architecture (Papanicolaou stain, magnification 200x). b and $\mathbf{c}$ The cells are markedly pleomorphic with enlarged irregular nuclei, macronucleoli and moderate lacy cytoplasm (magnification 400x and 600x). $\mathbf{d}$ Section of cell block show markedly atypical cells disposed in cribriform architecture. Frequent mitotic figures (black arrows) are also present (magnification 400x) 
SMA. Radiologically, the patient was staged as T3 N0 M0. It was recommended that the patient begin systemic chemotherapy with four cycles of FOLFIRINOX (Irinotecan $180 \mathrm{mg} / \mathrm{m}^{2}$; Oxaliplatin $85 \mathrm{mg} / \mathrm{m}^{2}$; 5-Fluorouracil $400 \mathrm{mg} / \mathrm{m}^{2}$; Folinic acid $400 \mathrm{mg} / \mathrm{m}^{2}$ ), after which she would be re-imaged for assessment of treatment efficacy.

The patient tolerated the four cycles without undue toxicity, after which she underwent re-staging with CT scans of the chest, abdomen, and pelvis. This revealed multiple non-calcified small pulmonary nodules detected bilaterally in the lower lobes, the largest of which measured $4 \mathrm{~mm}$. These nodules were previously not present and were thus considered suspicious for metastatic disease. As a result of the equivocal pulmonary nodules, resection was not indicated and the decision was made to continue FOLFIRINOX to further assess both local response, and the response of the potential metastatic nodules.

The patient received a further nine cycles of FOLFIRINOX. Follow up MRI revealed that the pancreatic lesion had impressively decreased in size from $3.9 \times 3.2 \mathrm{~cm}$ to $2.7 \times 2.3 \mathrm{~cm}$ compared to the previous CT (Fig. 1b). Furthermore, the lung lesions had remained stable since the last CT scan, raising the possibility that they were not metastatic. Given these results, and after discussion at multidisciplinary cancer conference, a resection was offered to the patient as a potentially curative treatment. She continued two more cycles of therapy before undergoing a pancreaticoduodenectomy, six weeks following discontinuation of FOLFIRINOX and 33 weeks from the date of diagnosis. No major technical difficulties were encountered in the procedure, although there was considerable tissue edema as expected from the chemotherapy. No vascular resection or reconstruction was required. Her postoperative course was complicated by pneumonia. She was discharged home on day 11. She was readmitted 9 days later with acute kidney injury, secondary to vomiting, poor intake and diarrhea, requiring one round of hemodialysis (peak creatinine $847 \mu \mathrm{mol} / \mathrm{L}$ or $9.58 \mathrm{mg} / \mathrm{dL}$, Dindo-Clavien grade $4 \mathrm{a})$.

Histological examination of the surgical specimen revealed no evidence of residual adenocarcinoma (Fig. 3), consistent with a complete response to treatment (College of American Pathologists grade 0) [22]. As is required in this situation, the entire specimen was submitted for histological assessment, confirming the complete pathological response (ypT0). Severe acute and chronic pancreatitis and areas of fibrosis were noted, together with scattered foci of grade 1 pancreatic intraepithelial neoplasia. All 23 resected lymph nodes were negative for malignancy (ypN0).

Following surgery, adjuvant therapy was not given. Her CT scans at 3 and 6 months postoperatively show no evidence of recurrence, with no appreciable change in her previously noted lung nodules. Her CA 19-9 is normal at $20 \mathrm{kU} / \mathrm{L}$. She remains disease-free 15 months after surgery, and 24 months after diagnosis. Given her strong family history of pancreatic cancer, she was referred for genetic testing. She was found to be a carrier of a BRCA2 mutation that is not uncommon among French Canadians (BRCA2: E3002K).

\section{Discussion}

The introduction of chemotherapy and radiotherapy as a possible neoadjuvant option in borderline resectable and locally advanced pancreatic cancer has yielded some positive results for patients with tumors that would have otherwise been unresectable. In a review of 111 studies, Gillen et al. concluded that approximately one-third of patients with initially unresectable locally advanced pancreatic cancer could become resectable following neoadjuvant therapy consisting of radiotherapy, chemotherapy, or a combination of the two [23]. Furthermore, successful resection following neoadjuvant therapy in locally advanced pancreatic cancer offers a median survival of 20.5 months, similar to that of R0 resections in patients

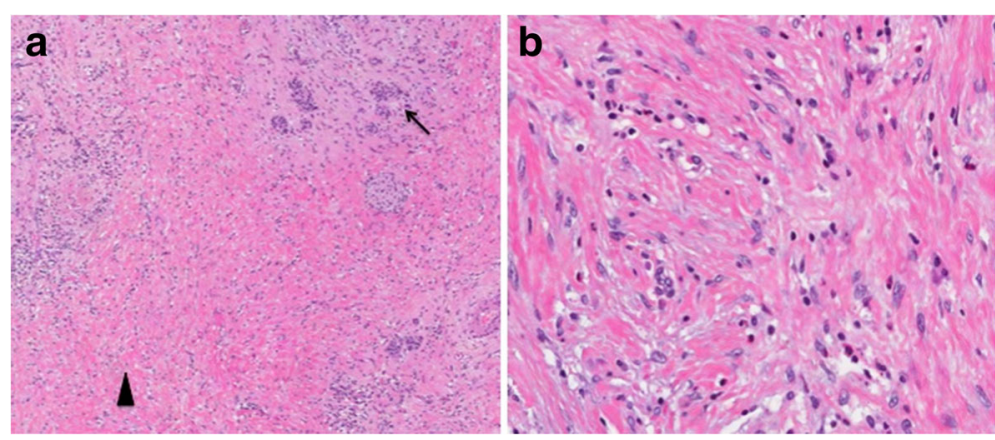

Fig. 3 Photomicrographs showing the cytomorphological findings of pancreatic specimens following surgical resection. a Low power view of section from resected pancreas showing residual acini and islets (arrow) while the previous tumor bed (arrowhead) shows fibrosis and a repair reaction. (Hematoxylin eosin; original magnification $\times 40$ ). $\mathbf{b}$ Higher magnification from the fibrotic area showing fibroblasts laying down collagen and a scattering of inflammatory cells (Hematoxylin eosin; original magnification $\times 200$ ) 
with initially resectable cases of pancreatic cancer [23]. Despite these positive results, a margin-positive resection conversely offers survival rates similar to that of patients with locally advanced pancreatic cancer who were treated with palliative intent as well as those who had metastatic disease at presentation [23]. Thus, the optimal management approach in locally advanced pancreatic cancer remains unclear, as there is currently only limited evidence to support neoadjuvant approaches.

In taking a neoadjuvant approach for locally advanced pancreatic cancer, the goal of treatment is to increase the likelihood of R0 resection, to obliterate micrometastatic disease, and to select for patients with favorable tumor biology by excluding those who progress on therapy [8]. Commonly used regimens have included gemcitabine alone, combination gemcitabine-platinum, as well as chemoradiotherapy using 5-FU or gemcitabine as chemosensitizers [24]. The optimal neoadjuvant approach in borderline resectable pancreatic cancer is still under investigation, but similarly to locally advanced pancreatic cancer, common approaches involve chemoradiotherapy or initial chemotherapy followed by radiotherapy [25]. The latter approach minimizes toxic side effects of radiotherapy and selects for patients without early metastasis while also offering potential tumour reduction [26]. At our institution, patients with both borderline resectable and locally advanced pancreatic cancer are managed initially with FOLFIRINOX as a potentially neoadjuvant approach. Patients are re-imaged after 4-6 cycles. To be considered an operative candidate, patients with borderline resectable pancreatic cancer must demonstrate stable disease or regression, while patients with locally advanced pancreatic cancer must demonstrate regression. These decisions are all made at a multidisciplinary cancer conference. Most of the existing trials for neoadjuvant therapy have included chemoradiotherapy and at this point the relative contributions of chemotherapy and radiotherapy are not well understood [2733].

FOLFIRINOX represents a new generation of efficacious combination chemotherapy regimens that may be utilized to treat patients with similar cases of pancreatic cancer. The efficacy of FOLFIRINOX was first demonstrated in a study by Conroy et al. in patients with unresectable pancreatic cancer [34]. A subsequent trial reported a median survival of 11.1 months in patients with metastatic pancreatic cancer who had received FOLFIRINOX as compared to a median survival of 6.8 months in patients receiving gemcitabine [35]. However, despite these results, the uptake of FOLFIRINOX into the arsenal of therapeutic options for pancreatic cancer has been slow due to concerns of toxicity. This is especially the case for locally advanced pancreatic cancer due to the paucity of data supporting FOLFIRINOX as a neoadjuvant option for this type of potentially resectable pancreatic cancer.

There is much hope that FOLFIRINOX could usher in a new era of downstaging of borderline resectable pancreatic cancer, allowing $\mathrm{R} 0$ resection. In a study of 18 patients with borderline resectable pancreatic cancer who were given FOLFIRINOX, 12 patients underwent pancreatectomy with negative margins [36]. However, this report is the first to describe a patient who achieved pCR with FOLFIRINOX alone. One example, reported in 2013 by Hartlapp et al., described a patient with locally advanced pancreatic cancer treated initially with nab-paclitaxel and gemcitabine which was eventually switched to FOLFIRINOX alone, resulting in pCR [5]. In their report, nab-paclitaxel and gemcitabine ultimately led to an increase in the level of CA19-9, prompting their switch to FOLFIRINOX. Pathological analysis of the pancreatic head in their patient revealed no viable cancer cells but the specimen did contain residual pancreatic intraepithelial neoplasia. Of note, Hartlapp et al. speculated that their preceding use of nab-paclitaxel might have played a vital role in increasing delivery of the subsequent FOLFIRINOX into the tumor cells.

In 2015, Valeri et al. were the first to report a patient with locally advanced pancreatic cancer who achieved pCR following neoadjuvant treatment with FOLFIRINOX alone (Table 1) [21]. Their patient had a locally advanced cancer of the pancreatic head that was treated with 8 cycles of FOLFIRINOX until restaging by CT scan demonstrated complete disappearance of the tumor [21]. Of note, the preoperative histology results for their patient described an undifferentiated carcinoma, which is a rare malignant epithelial neoplasm with dismal survival rates [21]. In a 2013 study of 25 patients with either unresectable or borderline resectable disease, Boone et al. also achieved pCR in one patient, although the details of this patient were not reported [14]. In a 2015 study by Blazer et al. of 25 locally advanced and 18 borderline resectable pancreatic cancer patients receiving modified FOLFIRINOX regimens, radiographic complete response was obtained in 9 patients. However, this study also included some patients who received radiation therapy. The outcomes were not sub-divided by treatment group, and therefore the effects of FOLFIRINOX alone could not be extrapolated [37].

Complete pathological response in the context of pancreatic cancer is a rare outcome. The probability of $\mathrm{PCR}$ following various neoadjuvant therapy approaches in pancreatic cancer has been shown to be $3.6 \%$, while the partial response rate is $30.6 \%$ [23]. In patients with borderline resectable or locally advanced pancreatic cancer, neoadjuvant therapy has been shown to lead to PCR in $13.6 \%$ of patients [38]. However, these studies considered all forms of neoadjuvant therapy and currently, 
Table 1 Outcomes of neoadjuvant FOLFIRINOX regimens in locally advanced and borderline resectable pancreatic cancer

\begin{tabular}{|c|c|c|c|c|c|c|c|c|}
\hline Authors & $\begin{array}{l}\text { Journal, } \\
\text { Year }\end{array}$ & $\begin{array}{l}\text { Number of } \\
\text { Patients }\end{array}$ & $\begin{array}{l}\text { Staging } \\
\text { System }\end{array}$ & $\begin{array}{l}\text { Duration } \\
\text { (Cycles) }\end{array}$ & $\begin{array}{l}\text { Radiographic } \\
\text { Response }\end{array}$ & $\begin{array}{l}\text { Surgical } \\
\text { Resection }\end{array}$ & R0 Rate & $\begin{array}{l}\text { Pathological } \\
\text { Results }\end{array}$ \\
\hline Blazer et al. & $\begin{array}{l}\text { Ann Surg Oncol } \\
2015\end{array}$ & $\begin{array}{l}25 \text { LAPC } \\
18 \text { BRPC }\end{array}$ & $\begin{array}{l}\text { AHPBA/ } \\
\text { SSO/ } \\
\text { SSAT }\end{array}$ & $\begin{array}{l}4.9 \\
\text { (mean) }\end{array}$ & NA & NA & NA & NA \\
\hline Boone et al. [14] & Surg Oncol, 2013 & $\begin{array}{l}13 \text { LAPC } \\
12 \text { BRPC }\end{array}$ & $\begin{array}{l}\text { AHPBA/ } \\
\text { SSO/ } \\
\text { SSAT }\end{array}$ & 5 (mean) & $\begin{array}{l}\text { PD } 1 \\
\text { Intolerable SE } 1\end{array}$ & $5 / 11$ & $4 / 5$ & $\begin{array}{l}1 \text { CAP g0 } \\
4 \text { CAP g1 }\end{array}$ \\
\hline Gunturu et al. [54] & Med Oncol, 2013 & 16 LAPC & NR & $\begin{array}{l}11 \\
\text { (median) }\end{array}$ & $\begin{array}{l}\text { PR } 8 \\
\text { SD } 7 \\
\text { PD } 0\end{array}$ & $2 / 16$ & $N R$ & $\begin{array}{l}1 \text { near pCR } \\
(2 \mathrm{~mm} \text { residual tumor) }\end{array}$ \\
\hline Hosein et al. [55] & BMC Cancer, 2012 & $\begin{array}{l}14 \text { LAPC } \\
4 \text { BRPC }\end{array}$ & $\begin{array}{l}\text { AHPBA/ } \\
\text { SSO/ } \\
\text { SSAT }\end{array}$ & 6 (median) & $\begin{array}{l}\text { LAPC (1 PD, } 9 \text { RT) } \\
\text { BRPC (1 RT) }\end{array}$ & $\begin{array}{l}\operatorname{LAPC}(3 / \\
14) \\
\operatorname{BRPC}(3 / 4)\end{array}$ & $\begin{array}{l}\text { LAPC (2/ } \\
3) \\
\text { BRPC (3/ } \\
3)\end{array}$ & NR \\
\hline $\begin{array}{l}\text { Khushman et al. } \\
\text { [56] }\end{array}$ & Pancreatology, 2015 & 25 LAPC & $\begin{array}{l}\text { AHPBA/ } \\
\text { SSO/ } \\
\text { SSAT }\end{array}$ & 8 (median) & PD 2 & $10 / 25$ & $7 / 10$ & NR \\
\hline Nitsche et al. [18] & $\begin{array}{l}\text { Ann Surg Oncol, } \\
2015\end{array}$ & $\begin{array}{l}14 \text { LAPC/ } \\
\text { BRPC }\end{array}$ & NCCN & 7 (median) & $6 \mathrm{PR}, 6 \mathrm{SD}, 1 \mathrm{PD}$ & $0 / 14$ & $N R$ & NR \\
\hline Peddi et al. [57] & JOP, 2012 & $\begin{array}{l}19 \text { LAPC } \\
4 \text { BRPC }\end{array}$ & NR & 4 (median) & $\begin{array}{l}1 \mathrm{rCR}, 5 \mathrm{PR}, 9 \mathrm{SD}, 3 \\
\mathrm{PD}\end{array}$ & $4 / 23$ & $N R$ & NR \\
\hline Valeri et al. [21] & Pancreatology, 2014 & 1 LAPC & MDA & 8 & $N R$ & $1 / 1$ & $1 / 1$ & $1 \mathrm{pCR}$ \\
\hline
\end{tabular}

LAPC locally advanced pancreatic cancer, BRPC borderline resectable pancreatic cancer, AHPBA Americas Hepatopancreatobiliary Association, SSO Society of Surgical Oncology, SSAT Society for Surgery of the Alimentary Tract, NA not available, $P D$ progressive disease, $S E$ side effects, $P R$ partial remission, $S D$ stable disease, $r C R$ radiological complete response, CAP College of American Pathologists grading system, NR not reported, NCCN National Comprehensive Cancer Network, MDA M.D. Anderson

most existing reports of pCR in pancreatic cancer involve chemoradiation rather than chemotherapy alone [6, 15-20, 39-49]. Other reports of complete responses have been only radiologically confirmed [34, 50-52]. There are presently multiple definitions for locally advanced and borderline resectable pancreatic cancer which have made it difficult to extrapolate conclusions on the efficacy of FOLFIRINOX as most current studies include heterogeneous patient populations [53].

\section{Conclusion}

The current work presented a rare occurrence of complete pathological response in a patient with borderline resectable pancreatic cancer following treatment with FOLFIRINOX. Consistent adoption and reporting of resectability classification in the initial staging of pancreatic cancers will allow for more homogenous study populations and a better assessment of the impact of neoadjuvant therapies in borderline resectable and locally advanced pancreatic cancer.

\section{Acknowledgements}

None.

Funding

No sources of funding were utilized in the preparation of this report.

Availability of data and materials

None.
Authors' contributions

MG compiled all information relating to the patient and wrote the manuscript. SB provided critical guidance, revisions, and mentoring for MG throughout the writing process. TM, HS, and GM were involved in the care of the patient and revised the manuscript. All authors read and approved the final manuscript.

\section{Authors' information}

No additional information.

\section{Competing interests}

GM has received a speaker's honorarium from Sanofi Canada.

\section{Consent for publication}

Consent to publish the details outlined in this case report was obtained from the patient. A copy of the written consent is available for review.

Ethics approval and consent to participate

Not applicable.

\section{Author details}

${ }^{1}$ Faculty of Medicine, University of Ottawa, 451 Smyth Rd, K1H 8 M5 Ottawa, Canada. ${ }^{2}$ Department of Surgery, Division of General Surgery, University of Ottawa, 451 Smyth Rd, K1H 8 M5 Ottawa, Canada. ${ }^{3}$ Department of Pathology and Laboratory Medicine, University of Ottawa, 501 Smyth Rd, K1H 8 L6 Ottawa, Canada. ${ }^{4}$ Department of Surgery, Liver and Pancreas Unit, University of Ottawa, 501 Smyth Rd, K1H 8 L6 Ottawa, Canada.

Received: 25 April 2016 Accepted: 29 September 2016

Published online: 10 October 2016

References

1. Bond-Smith G, Banga N, Hammond TM, Imber CJ. Pancreatic adenocarcinoma. BMJ (Clinical research ed). 2012;344:e2476.

2. Hidalgo M. Pancreatic cancer. N Engl J Med. 2010;362:1605-17. 
3. Rhim AD, Mirek ET, Aiello NM, Maitra A, Bailey JM, McAllister F, Reichert M, Beatty GL, Rustgi AK, Vonderheide $\mathrm{RH}$, et al. Emt and dissemination precede pancreatic tumor formation. Cell. 2012;148:349-61.

4. Haeno H, Gonen M, Davis MB, Herman JM, lacobuzio-Donahue CA, Michor F. Computational modeling of pancreatic cancer reveals kinetics of metastasis suggesting optimum treatment strategies. Cell. 2012;148:362-75.

5. Hartlapp I, Muller J, Kenn W, Steger U, Isbert C, Scheurlen M, Germer CT, Einsele H, Kunzmann V. Complete pathological remission of locally advanced, unresectable pancreatic cancer (lapc) after intensified neoadjuvant chemotherapy. Onkologie. 2013;36:123-5.

6. Elias A, Chatzizacharias NA, Xanthis A, Corrie P, Davies S, Brais RJ, Jamieson NV, Praseedom RK, Huguet E, Harper SJ, et al. Salvage pancreaticoduodenectomy after complete response to chemoradiotherapy for a previously unresectable pancreatic adenosquamous carcinoma: a case report. Medicine. 2015;94:e499.

7. Cascinu S, Falconi M, Valentini V, Jelic S. Pancreatic cancer: Esmo clinical practice guidelines for diagnosis, treatment and follow-up. Ann Oncol. 2010; 21 Suppl 5:v55-8.

8. Varadhachary GR, Tamm EP, Abbruzzese J, Xiong HQ, Crane $\mathrm{CH}$, Wang $\mathrm{H}$, Lee JE, Pisters PW, Evans DB, Wolff RA. Borderline resectable pancreatic cancer: definitions, management, and role of preoperative therapy. Ann Surg Oncol. 2006;13:1035-46.

9. Tempero MA, Malafa MP, Behrman SW, 3rd Benson AB, Casper ES, Chiorean EG, Chung V, Cohen SJ, Czito B, Engebretson A, et al. Pancreatic adenocarcinoma, version 2.2014: Featured updates to the nccn guidelines. J Natl Compr Canc Netw. 2014;12:1083-93.

10. Lopez NE, Prendergast C, Lowy AM. Borderline resectable pancreatic cancer: definitions and management. World J Gastroenterol. 2014;20:10740-51.

11. Callery MP, Chang KJ, Fishman EK, Talamonti MS, William Traverso L, Linehan DC. Pretreatment assessment of resectable and borderline resectable pancreatic cancer: expert consensus statement. Ann Surg Oncol. 2009:16:1727-33.

12. Lorenzen S, Thuss-Patience P, Al-Batran SE, Lordick F, Haller B, Schuster T, Pauligk C, Luley K, Bichev D, Schumacher G, et al. Impact of pathologic complete response on disease-free survival in patients with esophagogastric adenocarcinoma receiving preoperative docetaxel-based chemotherapy. Ann Oncol. 2013;24:2068-73.

13. Zhao Q, Rashid A, Gong Y, Katz MH, Lee JE, Wolf R, Balachandran A, Varadhachary GR, Pisters PW, Wang $H$, et al. Pathologic complete response to neoadjuvant therapy in patients with pancreatic ductal adenocarcinoma is associated with a better prognosis. Ann Diagn Pathol. 2012;16:29-37.

14. Boone BA, Steve J, Krasinskas AM, Zureikat AH, Lembersky BC, Gibson MK, Stoller RG, Zeh HJ, Bahary N. Outcomes with folfirinox for borderline resectable and locally unresectable pancreatic cancer. J Surg Oncol. 2013; 108:236-41.

15. Ferrone CR, Marchegiani G, Hong TS, Ryan DP, Deshpande V, McDonnell El, Sabbatino F, Santos DD, Allen JN, Blaszkowsky LS, et al. Radiological and surgical implications of neoadjuvant treatment with folfirinox for locally advanced and borderline resectable pancreatic cancer. Ann Surg. 2015;261: $12-7$

16. Mellon EA, Hoffe SE, Springett GM, Frakes JM, Strom TJ, Hodul PJ, Malafa MP, Chuong MD, Shridhar R. Long-term outcomes of induction chemotherapy and neoadjuvant stereotactic body radiotherapy for borderline resectable and locally advanced pancreatic adenocarcinoma. Acta oncologica (Stockholm, Sweden). 2015;54:979-85.

17. Moorcraft SY, Khan K, Peckitt C, Watkins D, Rao S, Cunningham D, Chau I. Folfirinox for locally advanced or metastatic pancreatic ductal adenocarcinoma: the royal marsden experience. Clin Colorectal Cancer. 2014;13:232-8

18. Nitsche U, Wenzel P, Siveke JT, Braren R, Holzapfel K, Schlitter AM, Stoss C, Kong B, Esposito I, Erkan M, et al. Resectability after first-line folfirinox in initially unresectable locally advanced pancreatic cancer: a single-center experience. Ann Surg Oncol. 2015;22 Suppl 3:1212-20.

19. Paniccia A, Edil BH, Schulick RD, Byers JT, Meguid C, Gajdos C, McCarter MD. Neoadjuvant folfirinox application in borderline resectable pancreatic adenocarcinoma: a retrospective cohort study. Medicine. 2014;93:e198.

20. Pietrasz D, Marthey L, Wagner M, Blanc JF, Laurent C, Turrini O, Raoul JL, Terrebonne E, Hentic O, Trouilloud I, et al. Pathologic major response after folfirinox is prognostic for patients secondary resected for borderline or locally advanced pancreatic adenocarcinoma: an ageo-french, prospective, multicentric cohort. Ann Surg Oncol. 2015;22 Suppl 3:1196-205.
21. Valeri S, Borzomati D, Nappo G, Perrone G, Santini D, Coppola R. Complete pathological response after folfirinox for locally advanced pancreatic cancer. the beginning of a new era? Case report and review of the literature. Pancreatology. 2014;14:425-30.

22. Washington MK, Berlin J, Branton PA, Burgart LJ, Carter DK, Compton CC, Fitzgibbons PL, Frankel WL, Jessup JM, Kakar S, et al. Protocol for the examination of specimens from patients with carcinoma of the distal extrahepatic bile ducts. Arch Pathol Lab Med. 2010;134:e8-e13.

23. Gillen S, Schuster T, Gillen S, Schuster T, Meyer Zum Buschenfelde C, Friess $\mathrm{H}$, Kleeff J. Preoperative/neoadjuvant therapy in pancreatic cancer: a systematic review and meta-analysis of response and resection percentages. PLoS Med. 2010;7:e1000267.

24. Katz MH, Fleming JB, Bhosale P, Varadhachary G, Lee JE, Wolff R, Wang H, Abbruzzese J, Pisters PW, Vauthey JN, et al. Response of borderline resectable pancreatic cancer to neoadjuvant therapy is not reflected by radiographic indicators. Cancer. 2012;118:5749-56.

25. Seufferlein T, Bachet JB, Van Cutsem E, Rougier P. Pancreatic adenocarcinoma: esmo-esdo clinical practice guidelines for diagnosis, treatment and follow-up. Ann Oncol. 2012;23 Suppl 7:vii33-40.

26. Heinemann V, Haas M, Boeck S. Neoadjuvant treatment of borderline resectable and non-resectable pancreatic cancer. Ann Oncol. 2013;24:2484-92.

27. Stokes JB, Nolan NJ, Stelow EB, Walters DM, Weiss GR, de Lange EE, Rich TA, Adams RB, Bauer TW. Preoperative capecitabine and concurrent radiation for borderline resectable pancreatic cancer. Ann Surg Oncol. 2011;18:619-27.

28. Chun YS, Milestone BN, Watson JC, Cohen SJ, Burtness B, Engstrom PF, Haluszka O, Tokar JL, Hall MJ, Denlinger CS, et al. Defining venous involvement in borderline resectable pancreatic cancer. Ann Surg Oncol. 2010;17:2832-8.

29. Leone F, Gatti M, Massucco P, Colombi F, Sperti E, Campanella D, Regge D, Gabriele P, Capussotti L, Aglietta M. Induction gemcitabine and oxaliplatin therapy followed by a twice-weekly infusion of gemcitabine and concurrent external-beam radiation for neoadjuvant treatment of locally advanced pancreatic cancer: a single institutional experience. Cancer. 2013;119:277-84.

30. Kim EJ, Ben-Josef E, Herman JM, Bekaii-Saab T, Dawson LA, Griffith KA, Francis IR, Greenson JK, Simeone DM, Lawrence TS, et al. A multi-institutional phase 2 study of neoadjuvant gemcitabine and oxaliplatin with radiation therapy in patients with pancreatic cancer. Cancer. 2013;119:2692-700.

31. Takahashi H, Ohigashi H, Gotoh K, Marubashi S, Yamada T, Murata M, loka T, Uehara $\mathrm{H}$, Yano M, Ishikawa O. Preoperative gemcitabine-based chemoradiation therapy for resectable and borderline resectable pancreatic cancer. Ann Surg. 2013;258:1040-50.

32. Kang CM, Chung YE, Park JY, Sung JS, Hwang HK, Choi HJ, Kim H, Song SY, Lee WJ. Potential contribution of preoperative neoadjuvant concurrent chemoradiation therapy on margin-negative resection in borderline resectable pancreatic cancer. J Gastrointest Surg. 2012;16:509-17.

33. Chuong MD, Hayman TJ, Patel MR, Russell MS, Malafa MP, Hodul PJ, Springett GM, Choi J, Shridhar R, Hoffe SE. Comparison of 1-, 2-, and 3-dimensional tumor response assessment after neoadjuvant gtx-rt in borderline-resectable pancreatic cancer. Gastrointest Cancer Res. 2011;4:128-34.

34. Conroy $T$, Paillot B, Francois E, Bugat R, Jacob JH, Stein U, Nasca S, Metges $J \mathrm{P}$, Rixe $\mathrm{O}$, Michel $\mathrm{P}$, et al. Irinotecan plus oxaliplatin and leucovorinmodulated fluorouracil in advanced pancreatic cancer-a groupe tumeurs digestives of the federation nationale des centres de lutte contre le cancer study. J Clin Oncol. 2005;23:1228-36.

35. Conroy T, Desseigne F, Ychou M, Bouche O, Guimbaud R, Becouarn Y, Adenis A, Raoul JL, Gourgou-Bourgade S, de la Fouchardiere C, et al. Folfirinox versus gemcitabine for metastatic pancreatic cancer. N Engl J Med. 2011;364:1817-25.

36. Christians KK, Tsai S, Mahmoud A, Ritch P, Thomas JP, Wiebe L, Kelly T, Erickson $B$, Wang $H$, Evans DB, et al. Neoadjuvant folfirinox for borderline resectable pancreas cancer: a new treatment paradigm? Oncologist. 2014;19:266-74.

37. Blazer M, Wu C, Goldberg RM, Phillips G, Schmidt C, Muscarella P, Wuthrick E, Williams TM, Reardon J, Ellison EC, et al. Neoadjuvant modified (m) folfirinox for locally advanced unresectable (lapc) and borderline resectable (brpc) adenocarcinoma of the pancreas. Ann Surg Oncol. 2015;22:1153-9.

38. Barugola G, Partelli S, Crippa S, Capelli P, D'Onofrio M, Pederzoli P, Falconi M. Outcomes after resection of locally advanced or borderline resectable pancreatic cancer after neoadjuvant therapy. Am J Surg. 2012;203:132-9.

39. Khan AZ, Pitsinis V, Mudan SS. Complete pathological response following down-staging chemoradiation in locally advanced pancreatic cancer: challenging the boundaries. World J Gastroenterol. 2007;13:6433-5. 
40. Galindo J, Gabrielli M, Guerra JF, Cassina JC, Garrido M, Jarufe N, Borghero Y, Madrid J, Zoroquiain P, Roa JC, et al. Neoadjuvant chemoradiation therapy for borderline pancreatic adenocarcinoma: report of two cases. World J Surg Oncol. 2013;11:37.

41. Magnin V, Moutardier V, Giovannini MH, Lelong B, Giovannini M, Viret F, Monges G, Bardou VJ, Alzieu C, Delpero JR. Neoadjuvant preoperative chemoradiation in patients with pancreatic cancer. Int J Radiat Oncol Biol Phys. 2003;55:1300-4.

42. Magnin V, Viret F, Moutardier V, Lelong B, Giovannini M, Monges G, Delpero JR. Complete pathologic responses to preoperative chemoradiation in two patients with adenocarcinoma of the pancreas. Pancreas. 2004;28:103-4.

43. Moutardier V, Magnin V, Turrini O, Viret F, Hennekinne-Mucci S, Goncalves A, Pesenti C, Guiramand J, Lelong B, Giovannini M, et al. Assessment of pathologic response after preoperative chemoradiotherapy and surgery in pancreatic adenocarcinoma. Int J Radiat Oncol Biol Phys. 2004:60:437-43.

44. Polistina F, Costantin G, Casamassima F, Francescon P, Guglielmi R, Panizzoni G, Febbraro A, Ambrosino G. Unresectable locally advanced pancreatic cancer: A multimodal treatment using neoadjuvant chemoradiotherapy (gemcitabine plus stereotactic radiosurgery) and subsequent surgical exploration. Ann Surg Oncol. 2010;17:2092-101.

45. Rajagopalan MS, Heron DE, Wegner RE, Zeh HJ, Bahary N, Krasinskas AM, Lembersky B, Brand R, Moser AJ, Quinn AE, et al. Pathologic response with neoadjuvant chemotherapy and stereotactic body radiotherapy for borderline resectable and locally-advanced pancreatic cancer. Radiat. 2013;8:254.

46. Reni M, Cereda S, Balzano G, Passoni P, Rognone A, Zerbi A, Nicoletti R, Mazza E, Arcidiacono PG, Di Carlo V, et al. Outcome of upfront combination chemotherapy followed by chemoradiation for locally advanced pancreatic adenocarcinoma. Cancer Chemother Pharmacol. 2009;64:1253-9.

47. White RR, Hurwitz HI, Morse MA, Lee C, Anscher MS, Paulson EK, Gottfried MR, Baillie J, Branch MS, Jowell PS, et al. Neoadjuvant chemoradiation for localized adenocarcinoma of the pancreas. Ann Surg Oncol. 2001;8:758-65.

48. White RR, Xie HB, Gottfried MR, Czito BG, Hurwitz HI, Morse MA, Blobe GC, Paulson EK, Baillie J, Branch MS, et al. Significance of histological response to preoperative chemoradiotherapy for pancreatic cancer. Ann Surg Oncol. 2005;12:214-21.

49. Wilkowski R, Thoma M, Bruns C, Wagner A, Heinemann V. Chemoradiotherapy with gemcitabine and continuous 5-fu in patients with primary inoperable pancreatic cancer. Jop. 2006;7:349-60.

50. Ghorani E, Wong HH, Hewitt C, Calder J, Corrie P, Basu B. Safety and efficacy of modified folfirinox for advanced pancreatic adenocarcinoma: a uk singlecentre experience. Oncology. 2015;89:281-7.

51. Mahaseth H, Brutcher E, Kauh J, Hawk N, Kim S, Chen Z, Kooby DA, Maithel SK, Landry J, El-Rayes BF. Modified folfirinox regimen with improved safety and maintained efficacy in pancreatic adenocarcinoma. Pancreas. 2013;42:1311-5.

52. Turner K, Levi Sandri GB, Boucher E, Henno S, Le Prise E, Meunier B, Boudjema K, Sulpice L. Complete radiological response of an initially locally advanced unresectable pancreatic cancer to chemoradiotherapy using folfirinox regimen: report of a case. Clin Res Hepatol Gastroenterol. 2015;39:e29-31.

53. Cooper AB, Tzeng CW, Katz MH: Treatment of borderline resectable pancreatic cancer. CurrTreat Opt Oncol. 14:293-310.

54. Gunturu KS, Yao X, Cong X, Thumar JR, Hochster HS, Stein SM, Lacy J. Folfirinox for locally advanced and metastatic pancreatic cancer: single institution retrospective review of efficacy and toxicity. Medical oncology (Northwood, London, England). 2013;30:361.

55. Hosein PJ, Macintyre J, Kawamura C, Maldonado JC, Ernani V, Loaiza-Bonilla A, Narayanan G, Ribeiro A, Portelance L, Merchan JR, et al. A retrospective study of neoadjuvant folfirinox in unresectable or borderline-resectable locally advanced pancreatic adenocarcinoma. BMC Cancer. 2012;12:199.

56. Khushman M, Dempsey N, Maldonado JC, Loaiza-Bonilla A, Velez M, Carcas L Dammrich D, Hurtado-Cordovi J, Parajuli R, Pollack T, et al. Full dose neoadjuvant folfirinox is associated with prolonged survival in patients with locally advanced pancreatic adenocarcinoma. Pancreatology. 2015;15:667-73.

57. Peddi PF, Lubner S, McWilliams R, Tan BR, Picus J, Sorscher SM, Suresh R, Lockhart AC, Wang J, Menias C, et al. Multi-institutional experience with folfirinox in pancreatic adenocarcinoma. Jop. 2013;13:497-501.

\section{Submit your next manuscript to BioMed Central and we will help you at every step:}

- We accept pre-submission inquiries

- Our selector tool helps you to find the most relevant journal

- We provide round the clock customer support

- Convenient online submission

- Thorough peer review

- Inclusion in PubMed and all major indexing services

- Maximum visibility for your research

Submit your manuscript at www.biomedcentral.com/submit
Ciomed Central 